\title{
Short Fibre Filler from Wood Residue for Polymeric Composite Materials
}

\section{Galia SHULGA ${ }^{1 *}$, Brigita NEIBERTE ${ }^{1}$, Anrijs VEROVKINS ${ }^{1}$, Sanita VITOLINA ${ }^{1}$, Jevgenijs JAUNSLAVIETIS ${ }^{1}$, Jurijs OZOLINS ${ }^{2}$}

\author{
${ }^{1}$ Latvian State Institute of Wood Chemistry, 27 Dzerbenes St., LV 1006, Riga, Latvia \\ ${ }^{2}$ Riga Technical University, 14/24 Azenes St., LV 1048, Riga, Latvia

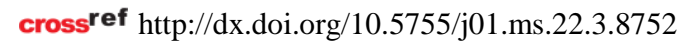

\section{Received 21 November 2014; accepted 17 July 2015}

\begin{abstract}
A wood residue - sawdust of the mechanical processing of aspen (Populus tremula) wood - was used to obtain a short fibre filler in the form of the modified microparticles $<250 \mu \mathrm{m}$ for polymeric composite materials. To reduce energy input for wood size reduction and the activation of the lignocellulosic matrix for modification, low temperature acid hydrolysis of the residue under mild conditions was carried out. The effect of the pre-treatment parameters (acid concentration, hydrolysis duration, hydromodulus) on the fractional and chemical composition as well as on the zeta potential and contact angle of the obtained filler were studied. A comparison of the mechanical properties (tensile, bending) of the composites filled with initial sawdust and hydrolysed microparticles modified with a non-stoichiometric polyelectrolyte complex showed a pronounced improvement of the mechanical properties of the composites filled with modified wood microparticles.

Keywords: short fibre filler, acid hydrolysis, polyelectrolyte complex, wood-polymer composite, mechanical properties.
\end{abstract}

\section{INRODUCTION}

The use of wood fibres for filling synthetic polymeric materials, due to their renewability, easy availability, low cost, biodegradability, light mass, enhanced filling degree, etc. is widely known [1-5]. In 2012, composites including wood fibres constituted almost $15 \%$ of the EU total composites production, with a volume of 352000 tonnes [6]. The presence of cellulose, hemicelluloses and lignin in the wood lignocellulosic matrix as a natural composite provides good mechanical properties of man-made composites. Aspen (Populus tremula), a representative of fast growing hardwood trees, annually gives the highest yield. Due to the relatively low cost and light weight, this species is widely used for manufacturing various hardwood articles. In Latvia, the residues formed due to aspen mechanical processing in the form of chips, bark and sawdust are used mainly for energetic needs. At the same time, these residues can be used as a feedstock for obtaining various value-added products, namely, a filler for obtaining wood-polymer composites (WPC) by incorporation of lignocellulosic fibres in a polymer matrix. WPC find wide application in building engineering, making interiors and internal finishes, garden and outdoor products, etc. The use of recycled synthetic polymers as a polymer matrix in wood-polymer composites is a promising practice for rational recovering of these wastes. However, the obtained composites not always have high mechanical indices due to the low compatibility between the synthetic matrix and the wood polymer in polymeric blends. The improvement of compatibility between polyolefins and wood fibres can be achieved by activation and modification of the fibre surface to increase its wettability $[7,8]$ towards the synthetic polymer matrix. It

\footnotetext{
* Corresponding author. Tel.: +371-67-572742; fax: +371-67-550635.

E-mail address: shulga@junik.lv (G. Shulga)
}

is known that, for the wood polymer composites filled with fibres having a high aspect ratio, the length of the fibre and its orientation in the polymer matrix are very important. The properties of the composites containing wood microparticles with a low aspect ratio are defined to a greater extent by the particle size, particle size distribution and particle charge. Smaller sizes of wood particles benefit their compatibility with the polymer matrix and favour the decrease in the melt viscosity of the wood-polymer blend during the processing. Wood particles $<250 \mu \mathrm{m}$ are commonly used for filling polymeric composites [9]. For obtaining a filler in the form of microparticles, wood has to be milled. Due to the enhanced considerable energy consumption and energy input, the milling of untreated wood is not economically beneficial. To facilitate and decrease the grinding and milling energy consumption, various technologies for pre-treatment of wood are known, namely, chemical, physico-chemical, physical, enzymes, etc. [10], which are directed toward decreasing the mechanical strength of the wood lignocellulosic matrix. Acid hydrolysis of wood is one of the most commonly used pre-treatment methods for size reduction of wood for its further processing, for example, in bioethanol production [11] or in wood thermomechanical pulping [12]. Such a type of hydrolysis can be realised using dilute or concentrated acids. As a rule, the dilute acid hydrolysis technology applies high temperatures $\left(>100^{\circ} \mathrm{C}\right)$ and enhanced pressures. On the other hand, very scarce information is available on the effect of low temperature hydrolysis $\left(<100{ }^{\circ} \mathrm{C}\right)$ with a dilute acid on the size reduction of wood after its milling and on the properties of the obtained wood microparticles. Such information is very useful for obtaining a lignocellulosic filler with defined properties for making wood-polymer composites. The cleavage of ether linkages in wood during hydrolysis is accompanied by changes in the functional groups' composition at its surface that leads to the chemical 
activation of the lignocellulosic matrix and facilitates its accessibility to modification for improving the compatibility between the wood filler and the synthetic polymer.

The aim of the present study was to obtain a short fibre filler from the aspen wood residue for obtaining woodpolymer composites, to characterise its properties and to compare the mechanical properties of the composites incorporating initial and modified hydrolysed aspen microparticles as a short fibre filler.

\section{EXPERIMENTAL DETAILS}

The aspen sawdust represented a residue of the industrial mechanical processing of aspen wood. The main part of its fractional composition $(\sim 70 \%)$ consisted of particles with a size ranging from $0.5 \mathrm{~mm}$ to $1 \mathrm{~mm}$. The elemental component composition of aspen wood determined with an Elementar Analysensysteme $\mathrm{GmbH}$ (Germany) was as follows: $48.77 \% \mathrm{C}, 6.25 \% \mathrm{H}$, $44.71 \% \mathrm{O}, 0.11 \% \mathrm{~N}$ and $0.16 \% \mathrm{~S}$. The composition of the residue was studied according to analytical chemical procedures - Klason and Kürschner ones - for lignin and cellulose, respectively [13]. The content of extractives in the residue represented the sum of the content of the wood substances dissolved in acetone, using a Soxlet extractor, and in hot water $\left(100{ }^{\circ} \mathrm{C}\right)$ during $3 \mathrm{~h}$. The content of cellulose $(50.5 \%)$, lignin $(18.5 \%)$, hemicelluloses $(26.1 \%)$, extractives $(4.5 \%)$ and ash $(0.4 \%)$ in aspen wood.

To reduce the strength of the lignocellulosic matrix in aspen wood, acid hydrolysis was carried out by using a 5-L three-neck flask equipped with a return condenser, a thermometer and a stirrer under the following conditions: $\mathrm{HCl}$ concentration of $0.05-0.5 \mathrm{~g} / \mathrm{dl}$, temperature $60^{\circ} \mathrm{C}$ and duration $1-7 \mathrm{~h}$ at a hydromodulus (sawdust/water mass ratio) of 1/10,1/20 and 1/50. After the hydrolysis, the treated residue was separated from the hydrolysate by filtration and dried, at first, at $60{ }^{\circ} \mathrm{C}$ for $48 \mathrm{~h}$ and then at $105{ }^{\circ} \mathrm{C}$ during a short time. The UV-spectra analysis of the obtained hydrolysates was performed with the help of an UV-VIS Spectrometer Genesys ${ }^{\mathrm{TM}} 10$ (Thermo, USA). The mass losses of the hydrolysed residue were used for calculating the amounts of the extracted materials - the water-soluble products formed as a result of wood hydrolysis. Milling was carried out with a planetary ball mill (Retsch, Germany) at $300 \mathrm{~min}^{-1}$ during $15 \mathrm{~min}$. The milled residue fractionation was performed by using Pulverizette 0 (Fritsch, Germany) with a set of sieves during $30 \mathrm{~min}$. The size distribution was investigated with a laser particle granulometer (Annalizetto-22 NanoTec, Fritsch, Germany). The shape of the finest microparticles was fixed by transmission electron microscopy (Leo 912 AB Omega microscope, Carl Zeiss, Germany). The microstructure of the hydrolysed wood particles was examined using a scanning electron microscope (Tescan 5136, Czech Republic). Advancing contact angle ( $\theta$ ) of the wood microparticles was measured with a tensiometer Kruss 100M (Kruss, Germany) by the Washburn method. With this aim, at first, the capillary constant for each wood sample was determined in n-hexane, whose contact angle was $0^{\circ}$. Zeta potential $(Z)$ of the microparticles was measured with a dynamic light scattering device Zetasizer Nano SZ (Malvern, UK) at $25^{\circ} \mathrm{C}$.

Modification was realised in a water suspension by the treatment of the hydrolysed microparticles $<250 \mu \mathrm{m}$ with a non-stoichiometric polyelectrolyte complex composed of a synthetic polycation and hardwood alkali lignin obtained under laboratory conditions at room temperature. After the modification, the modified wood microparticles were washed with distilled water to neutral $\mathrm{pH}$ and dried, at first, at room temperature and then at $60{ }^{\circ} \mathrm{C}$ for $48 \mathrm{~h}$.

For making the wood-polymer composite samples, recycled polypropylene (RPP) in a powder form was used as a thermoplastic polymer matrix. It had a density of $0.9 \mathrm{t} \mathrm{m}^{-3}$ and a melt flow index of $5.2 / 10 \mathrm{~min}\left(230^{\circ} \mathrm{C}\right.$, $2.16 \mathrm{~kg}$ ). The RPP content in the WPC samples was 30 mass \%. The raw blend consisting of RPP and the filler was mixed in a high-speed mechanical mixer (LZM-1M, Russia) before its processing. The samples for tensile and bending tests were prepared by the extrusion and moulding method using HAAKE MiniLab II and MiniJet II (ThermoScientific, Germany) at a temperature of $175-180^{\circ} \mathrm{C}$ and a circulation time of $10-15 \mathrm{~s}$. Mechanical tests were carried out in a universal machine "Zwick" (Zwick/Roell, Germany) with a load capacity of $0.5 \mathrm{kN}$ according to ASTM D638 [14] and EN ISO 178 [15] using a software programme TestXpert. Before testing, the samples were conditioned at $60{ }^{\circ} \mathrm{C}$ during $24 \mathrm{~h}$ and then placed in an exsiccator with phosphorus pentoxide. Five replicates were made for each mechanical testing, and standard deviation for each index was found.

\section{RESULTS AND DISCUSSION}

\subsection{Obtaining a short fibre filler from the aspen wood residue}

A study of the effect of the acid concentration in the low temperature hydrolysis $(1 \mathrm{~h}$ at a hydromodulus of $1 / 20$ ) on the amount of the released extracted materials, the water-soluble products formed as a result of wood hydrolysis and consisting of water-soluble extractives and lignocellulosic degradation products (low molecular hemicelluloses and lignin fragments), shows that, with applying $0.05 \mathrm{~g} / \mathrm{dl} \mathrm{HCl}$, the amount of the water-soluble products in the hydrolysate increases 1.6-1.8 times (Table 1) in comparison with the case of the hydrolysis in distilled water, but the yield of the hydrolysed solid product decreases to $97.8 \%$. The highest content of the water-soluble degraded products is in the hydrolysate obtained by the treatment of the residue with the highest $\mathrm{HCl}$ concentration $(0.5 \mathrm{~g} / \mathrm{dl})$ : their amount in the hydrolysate increases more than twice in comparison with the case of the hydrolysis in water, but the yield of the hydrolised sawdust decreases to $94.9 \%$. According to Table 1, the water-soluble degraded products are mainly hemicelluloses fragments, the amount of which in the residue decreases with increasing the content of the watersoluble degraded products in the obtained hydrolysates. The relative content of cellulose in the hydrolysed residue is enhanced with increasing the $\mathrm{HCl}$ concentration. As shown in Table 1 , at the $\mathrm{HCl}$ concentration $>0.15 \mathrm{~g} / \mathrm{dl}$, the amount of lignin aromatic fragments in the hydrolysate 
Table 1. Composition of the hydrolysed aspen residue depending on the acid concentration

\begin{tabular}{|c|c|c|c|r|c|}
\hline $\mathrm{HCl}, \mathrm{g} / \mathrm{dl}$ & Extractives, $\%$ & Cellulose, $\%$ & Lignin, $\%$ & Hemicelluloses, $\%$ & $\mathrm{O} / \mathrm{C}$ \\
\hline 0.00 & $2.2 \pm 0.2$ & $51.0 \pm 1.7$ & $18.5 \pm 1.2$ & $28.3 \pm 1.5$ & $26.1 \pm 0.1$ \\
\hline 0.05 & $3.9 \pm 0.3$ & $51.6 \pm 2.1$ & $18.5 \pm 1.3$ & $26.0 \pm 1.4$ & $24.7 \pm 0.3$ \\
\hline 0.10 & $4.6 \pm 0.3$ & $52.6 \pm 1,6$ & $18.5 \pm 1.4$ & $24.3 \pm 1.9$ & $24.1 \pm 0.2$ \\
\hline 0.15 & $4.9 \pm 0.4$ & $53.2 \pm 1.8$ & $18.5 \pm 1.5$ & $23.4 \pm 1.7$ & $23.8 \pm 0.2$ \\
\hline 0.30 & $5.0 \pm 0.5$ & $53.5 \pm 2.0$ & $18.2 \pm 1.3$ & $23.3 \pm 2.0$ & $23.6 \pm 0.2$ \\
\hline 0.50 & $5.1 \pm 0.3$ & $53.6 \pm 2.2$ & $18.0 \pm 1.4$ & $23.3 \pm 1.9$ & $23.4 \pm 0.1$ \\
\hline
\end{tabular}

starts to increase. This may confirm the UV-spectrum of the hydrolysate (Fig. 1) obtained by the residue hydrolysis with a $\mathrm{HCl}$ concentration of $0.30 \mathrm{~g} / \mathrm{dl}$, characterised by pronounced absorbance bands at 238, 288 and $338 \mathrm{~nm}$, which indicate the presence of biphenyl derivatives and aromatic fragments, containing non-etherified hydroxyl groups, and carbonyl and carboxyl groups of lignin.

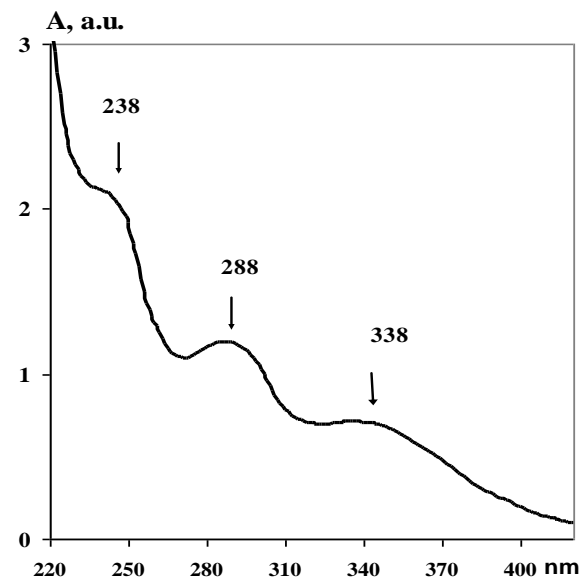

Fig. 1. UV absorbtion spectrum of the aspen hydrolysate obtained with $0.30 \mathrm{~g} / \mathrm{dl} \mathrm{HCl}$ solution

At the same time, the correlation between the released water-soluble hydrolysed products and the applied acid concentration has a saturation character. According to Table 1, the hydrolysis with the $\mathrm{HCl}$ concentration more than $0.15 \mathrm{~g} / \mathrm{dl}$ does not lead to an essential change in the amount of the water-soluble products, and the yield of the hydrolysed sawdust varies from $95.0 \%$ to $94.9 \%$. Additionally, the application of $\mathrm{HCl}$ with a concentration of more than $0.15 \mathrm{~g} / \mathrm{dl}$ increases the content of low molecular lignin fragments in the hydrolysate that is not rational, taking into account the reinforcement function of lignin in wood as well as the subsequent modification of the milled hydrolysed residue with the polyelectrolyte complex.

The results demonstrated in Fig. 2 reflect the effect of the hydrolysis duration, using a $0.15 \mathrm{~g} / \mathrm{dl} \mathrm{HCl}$ concentration, on the yield of the water-soluble substances.

It can be seen, that, with increasing hydrolysis time, the concentration of the extracted substances in the hydrolysate grows. Simultaneously, the relative content of cellulose increases from $51.0 \%$ to $54.3 \%$, but the yield of the hydrolysed residue decreases from $98.2 \%$ (in distilled water) to $94.6 \%$ after the hydrolysis time of $5 \mathrm{~h}$. The hydrolysis during $7 \mathrm{~h}$ caused the pass of the enhanced amount of the low molecular lignin fragment to the hydrolysate that was not favourable for obtaining short fibre filler for the composite. According to Fig. 3, with decreasing hydrolysis hydromodulus (mass ratio of the wood residue to water) from $1 / 10$ to $1 / 50$, the extractives' concentration in the hydrolysate, obtained with a $0.15 \mathrm{~g} / \mathrm{dl}$ $\mathrm{HCl}$ solution at a hydrolysis duration of $5 \mathrm{~h}$, is remarkably enhanced, but the yield of the hydrolysed residue decreases from $98.2 \%$ to $92.9 \%$.

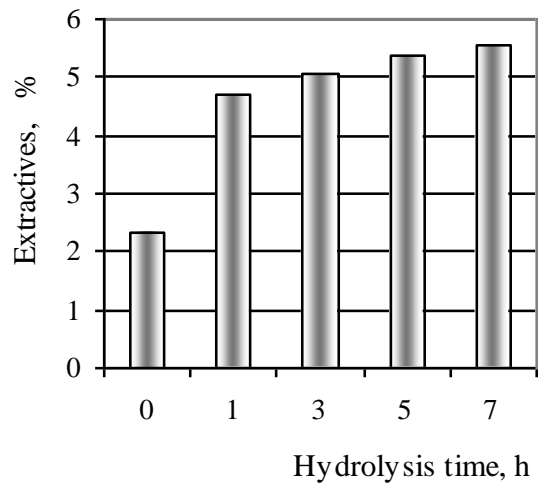

Fig. 2. Degraded products $v s$ hydrolysis time

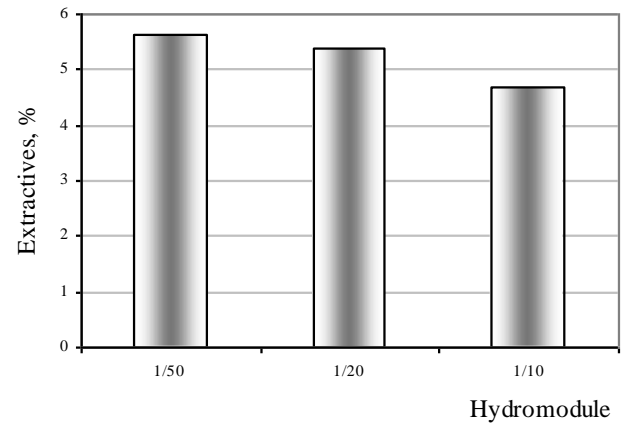

Fig. 3. Degraded products $v s$ hydromodulus

The components composition analysis of the hydrolysed residue obtained at a hydromodulus of 1/50 shows that the water-soluble products in the hydrolysate have mainly the hemicelluloses nature. However, the use of a hydrolysis hydromodulus of $1 / 50$, despite the absence of a great amount of lignin fragments, is not beneficial, because it diminishes the yield of the hydrolysed residue, and the hydrolysis in these conditions requires a considerable consumption of water.

The partial removal of hemicelluloses and lignin from the original lignocellulosic matrix due to the cleavage of glycoside ether bonds leads to the reduction of its mechanical strength. This is testified by the data represented in Table 2. It can be seen that, with increasing $\mathrm{HCl}$ concentration, the amount of fine wood particles in the fractional composition of the milled residue grows, but that of coarse particles with a size of more than $250 \mu \mathrm{m}$ decreases. In comparison with the case of the residue treated with water alone, the yield of the microparticles $<250 \mu \mathrm{m}$ in the milled residue hydrolysed with $0.5 \mathrm{~g} / \mathrm{dl}$ increases by almost $40 \%$. 
Table 2. Fractional composition of the milled hydrolysed aspen residue depending on the acid concentration

\begin{tabular}{|c|c|c|c|c|c|c|}
\hline \multirow{2}{*}{$\begin{array}{c}\text { Fraction, } \mu \mathrm{m} / \\
\mathrm{HCl} \text { concentration, } \mathrm{g} / \mathrm{dl}\end{array}$} & \multicolumn{5}{|c|}{ Content, $\mathrm{g} / 100 \mathrm{~g}$ of milled residue } \\
\cline { 2 - 7 } & water & 0.015 & 0.050 & 0.150 & 0.300 & 0.500 \\
\hline $\mathrm{d}>1000$ & $5.1 \pm 0,3$ & $2.2 \pm 0.1$ & 0 & 0 & 0 & 0 \\
\hline $1000>\mathrm{d} \geq 500$ & $14.3 \pm 0.7$ & $12.4 \pm 0.6$ & $11.4 \pm 0.6$ & $10,3 \pm 0.5$ & $9.9 \pm 0.5$ & $9.7 \pm 0.5$ \\
\hline $500>\mathrm{d} \geq 250$ & $35.5 \pm 1.8$ & $31.3 \pm 1.6$ & $30.7 \pm 1.5$ & $27.7 \pm 1.4$ & $27.4 \pm 1.4$ & $27.0 \pm 1.3$ \\
\hline $\mathrm{d}<250$ & $45.1 \pm 2.3$ & $54.1 \pm 2.7$ & $57.9 \pm 2.9$ & $62.0 \pm 3.1$ & $62.7 \pm 3.2$ & $63.3 \pm 3.2$ \\
\hline
\end{tabular}

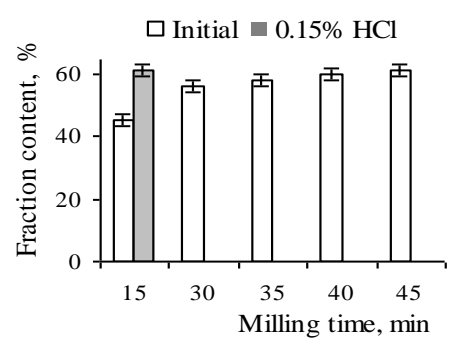

Fig. 4. Content of particles $<250 \mu \mathrm{m}$ for initial and hidrolysed aspen residue $v s$ milling time

At the same time, there is no essential difference in the yield of the microparticles $<250 \mu \mathrm{m}$ from the residue hydrolysed with a $0.15 \mathrm{~g} / \mathrm{dl} \mathrm{HCl}$ and a higher acid concentration.

It is known that the chemical pre-treatment of wood promotes the decreasing of the size reduction energy consumption. Fig. 4 shows the yield of the fraction of microparticles $<250 \mathrm{mg}$ in the milled initial residue and the residue hydrolysed under optimal pre-treatment conditions: $0.15 \mathrm{~g} / \mathrm{dl} \mathrm{HCl}$, hydromodulus $1 / 20$ and duration $5 \mathrm{~h}$, depending on the milling time. According to Fig. 4 , to achieve an approximately $62 \%$ yield of microparticles, the non-treated residue must be milled during 45 min against $15 \mathrm{~min}$ for the hydrolysed aspen by-product. This means a 3 -fold decrease in the milling time for obtaining the same amount of the fine particles $(<250 \mu \mathrm{m})$ in the case of the hydrolysed residue, hence, a 3-fold decrease of energy consumption for milling in comparison with the initial residue.

\subsection{Image and properties of hydrolysed wood microparticles}

The analysis of the particle size distribution within the fraction $<100 \mu \mathrm{m}$ showed that more than $50 \%$ of the fraction volume was occupied by the microparticles with sizes of $10-50 \mu \mathrm{m}$ (Fig. 5).

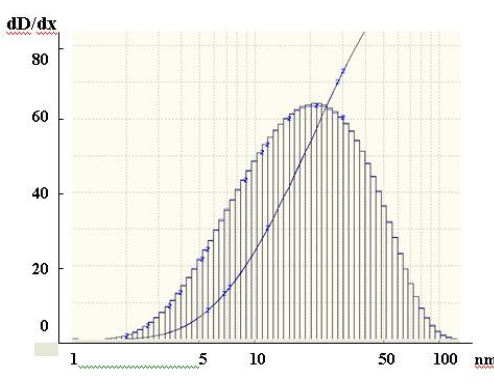

Fig. 5. Size distribution histogram of hydrolysed microparticles

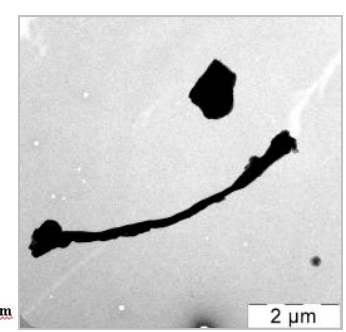

Fig. 6. TEM image of microparticles

The study of the obtained hydrolysed microparticles by TEM revealed the prevalence of two types of the microparticles' shape, namely, oval and extended ones (Fig. 6) with average length of $1-2 \mu \mathrm{m}$ and $6-8 \mu \mathrm{m}$, respectively. The low aspect ratio between the width and length of the obtained microparticles testifies their short fibre nature.

The cleavage of the glycosidic linkages in the lignocellulosic matrix influences its functional groups' content and composition. This confirms an increase in the values of $\mathrm{O} / \mathrm{C}$ with increasing applied $\mathrm{HCl}$ concentration (Table 1), indicating the growth of the content of oxygencontaining groups such as hydroxyl, carbonyl and carboxyl ones.
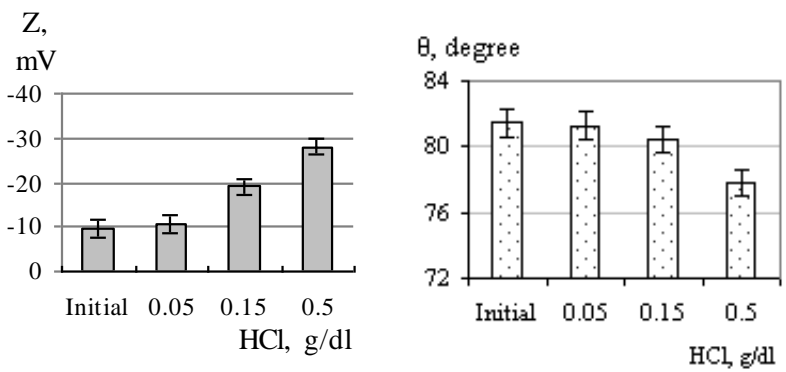

Fig. 7. Particles' zeta potential $v s \mathrm{HCl}$ concentration

Fig. 8. Particles' contact angle vs $\mathrm{HCl}$ concentration

According to Fig. 7, the $Z$ potential that characterises the charge of the particles increases with growing acid concentration. The minimal and maximal values of the $Z$ potential are assigned to the microparticles obtained from the milled initial residue and the residue hydrolysed with a high $\mathrm{HCl}$ concentration, appropriately. The presence of the negative charge at the surface of the microparticles favours their chemical modification.

It can be seen (Fig. 8) that the contact angle of the hydrolysed microparticles decreases from $81.3^{\circ}$ to $76.5^{\circ}$ with growing $\mathrm{HCl}$ concentration from $0.05 \mathrm{~g} / \mathrm{dl}$ to $0.5 \mathrm{~g} / \mathrm{dl}$. The noticed drop in the contact angle at the high $\mathrm{HCl}$ concentration, connected with the beginning of lignin removal from the wood matrix, is an undesirable phenomenon, because it can cause a remarkable enhancement in the hydrophilicity of the hydrolysed microparticles and increase their water sorption. Our study shows that the low temperature hydrolysis of the aspen wood residue under the found optimal conditions $(0.15 \mathrm{~g} / \mathrm{dl}$ $\mathrm{HCl}$, hydromodulus $1 / 20$ and duration $5 \mathrm{~h}$ ) is gentle and thus has a negligible effect on the morphology of aspen wood fine fibres that is testified by their SEM image given in Fig. 9.

This fact is very important from the viewpoint of the use of the obtained microparticles as a reinforcing filler in the polymeric composites, because the pronounced degraded lignocellulosic matrix is not able to improve the mechanical properties of synthetic polymers. 
Table 3. Mechanical properties of recycled polypropylene filled $(30 \%)$ with the microparticles $(<250 \mu \mathrm{m})$ from the initial and modified hydrolysed aspen residue

\begin{tabular}{|c|c|c|c|c|c|c|}
\hline Filler & $\begin{array}{c}\text { Tensile strength, } \\
\mathrm{MPa}\end{array}$ & $\begin{array}{c}\text { Tensile modulus, } \\
\mathrm{MPa}\end{array}$ & $\begin{array}{c}\text { Deformation, } \\
\%\end{array}$ & $\begin{array}{c}\text { Bending strength, } \\
\mathrm{MPa}\end{array}$ & $\begin{array}{c}\text { Bending modulus, } \\
\mathrm{MPa}\end{array}$ & $\begin{array}{c}\text { Deformation, } \\
\mathrm{mm}\end{array}$ \\
\hline RPP & $20.1 \pm 0.2$ & $495.1 \pm 8.0$ & $25.4 \pm 0.7$ & $29.9 \pm 0.30$ & $897.6 \pm 29.5$ & $9.3 \pm 0.2$ \\
\hline Initial particles & $25.5 \pm 0.3$ & $620.3 \pm 8.5$ & $12.8 \pm 0.8$ & $33.1 \pm 0.4$ & $1529.1 \pm 28.4$ & $6,8 \pm 0.2$ \\
\hline $\begin{array}{c}\text { Hydrolysed modified } \\
\text { particles }\end{array}$ & $34.4 \pm 0.4$ & $1030.5 \pm 9.9$ & $5.2 \pm 1.0$ & $39.9 \pm 0.5$ & $3750.4 \pm 25.5$ & $1.8 \pm 0.3$ \\
\hline
\end{tabular}

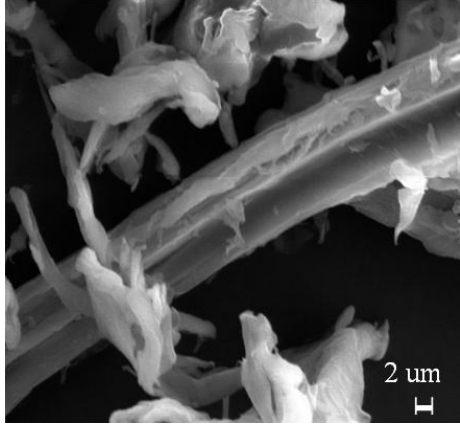

Fig. 9. SEM image of hydrolysed aspen residue

\subsection{Properties of composites filled with microparticles}

It is known that, to improve the compatibility between the polymer matrix and the wood filler in WPC, the lignocellulosic surface has to be modified. According to the literature data, with this aim, various chemical reagents including inorganic bases and acids, anhydrides, isocyanates, formaldehyde, silanes, phthaldehydic acid, acetylation, methylation and thermocatalytic treatment, etc. are applied [16-18]. All these techniques are directed mainly toward the enhancement of the interfacial adhesion between the wood particles and the polymer matrix in the composites by decreasing the free energy at the interface via increasing the physico-chemical interaction between the matrix and the filler particles.

In this work, to increase the interaction between the composite ingredients, the hydrolysed microparticles $<250 \mu \mathrm{m}$ were treated by the non-stoichiometric polyelectrolyte complex composed of a synthetic polycation and hardwood alkali lignin obtained under laboratory conditions in a water suspension at room temperature for $8 \mathrm{~h}$. Early, it has been shown [19] that polyelectrolyte complexes containing lignin are characterised by good surface-active and adhesion properties.

The mechanical properties of the recycled polymer and the RPP-based composites filled with the aspen microparticles $(<250 \mu \mathrm{m})$ from initial and modified hydrolysed residue with a filling of 30 mass $\%$ are shown in Table 3. According to the presented data, the obtained composites are characterised by an essential increase in the mechanical strength and stiffness in comparison with the recycled polypropylene.

The given results indicate also a pronounced improvement of the mechanical parameters for the composite filled with the modified microparticles, compared with the case of the composite filled with the unmodified particles, namely, the tensile strength at break and bending strength of the composites incorporating the modified particles increases almost 1.4 and 1.2 times, but tensile and bending modulus of rupture is enhanced 1.7 and 2.5 times, respectively. Simultaneously, the deformability of these composites essentially decreases, namely, elongation at break drops more than twice, but deflection ability diminishes more than 3 times in comparison with the case of the composite filled with the initial sawdust microparticles. Evidently, the introduction of nitrogen-containing groups at the wood particles' surface by its treatment with the polyelectrolyte complex promotes the interaction at the polymer matrix /wood filler interface due to the possible formation of a hydrogen linkages network between the nitrogen- and oxygencontaining groups at the filler surface and the hydroxyl groups of the recycled PP that decreases the interfacial free energy and can lead to the structuring of the interfacial layers. All these factors can have a favourable effect on the compatibility between the polymer matrix and the filler in the complex system.

\section{CONCLUSIONS}

Optimal parameters of the low temperature hydrolysis (acid concentration, duration, hydromodulus) of aspen sawdust with dilute hydrochloric acid for reducing its particle sizes $<250 \mu \mathrm{m}$ with the aim of their further chemical modification for obtaining a short fibre filler for WPC are found. Those hydrolysis parameters are compromised from the viewpoint of the lignocellulosic matrix destruction and the lignin content therein.

The partial acid hydrolysis of aspen sawdust leads to an essential drop in its milling time (3-fold) and to the enhanced yield of the finest wood particles in the milled sawdust, compared with the case of the non-treated sawdust.

The modification of the obtained microparticles by their treatment with a non-stoichiometric polyelectrolyte complex containing the polycation and hardwood alkali lignin improves the compatibility at the polymer matrix/ short fibre filler interface in the composite system. As a result, it considerably increases the mechanical properties (tensile, bending) and decreases the deformability of the composite filled with the modified aspen microparticles in comparison with the composite containing the particles from the non-hydrolysed residue.

\section{Acknowledgments}

The authors have received funding for this study from the Ministry of Education and Science of the Republic of Latvia for the State Research Programme. 


\section{REFERENCES}

1. Vroman, I., Tighzert, L. Biodegradable Polymers (Review) Materials 2 (2) 2009: pp. 307-344. http://dx.doi.org/10.3390/ma2020307

2. Bledzki, A. K., Faruk, O. Surface Roughness, Impact, and Odor Properties of Microcellular Wood Fiber Reinforced PP Composites: Cell Morphology Journal of Cellular Plastics 41 2005: pp. 539-550. http://dx.doi.org/10.1177/0021955X05059033

3. John, M. J., Anandjiwala, R. D. Recent Developments in Chemical Modification and Characterization of Natural Fibre-reinforced Composites Polymer Composites 29 (2) 2008: pp. 187-207.

4. Shulga, G., Betkers, T., Klyavinsh, J. Application of a Triple Interpolymer Complex Based on a Wood Polymer in Manufacture of Lignocellulosic Composites Materials Science (Medžiagotyra) 9 (1) 2002: pp. 83-87.

5. Shulga, G., Neiberte, B., Verovkins, A., Laka, M., Chernyavskaya, S., Shapovalov, V., Valenkov, A., Tavroginskaya, M. The New Polymer Composites Integrating Modified Wood Originated Products Proceedings of the International Conference "Italic-5", September 1-4, 2009, Varenna, Italy, 2009: pp. 185-188.

6. Carus, M., Eder, A., Dammer, L., Korte, H., Scholz, L., Essel, R., Breitmayer, E. Wood-plastic Composites (WPC) and Natural FIbre Composites (NFC): European and Global Markets 2012 and Future Trends. Nova Institut $\mathrm{GmbH}$, 2012.

http://www.nova-institut.de/download/market_study_wpc_nfc_short_version

7. Farsi, M. Effect of Surface Modification on Thermomechanical Behaviour of Wood-polymer Composite Asian Journal of Chemistry 24 (6) 2012: pp. 2775-2779.

8. Ho, M., Wang, H., Lee, J-H., Ho, C., Lau, K., Leng, J., Hui, D. Critical Factors on Manufacturing Processes of Natural Fibre Composites Composites $\quad B \quad 43$ 2012: pp. 3549-3562.

9. Cordeiro, N., Ornelas, M., Ashori, A., Sheshmani, S., Norouzi, H. Investigation on the Surface Properties of Chemically Modified Natural Fibers Using Inverse Gas Chromatography Carbohydrate Polymers 87 2012: pp. $2367-2375$.
10. Mosier, N., Wyman, C., Dale, B., Elander, R., Lee, Y. Y., Holtzapple, M. Features of Promising Technologies for Pretreatment of Lignocellulosic Biomass Bioresource Technology 96 (6) 2005: pp. 673-686.

11. Kumar, P., Barrett, D. M., Delwiche, M. J., Stroeve, P. Methods for Pre-treatment of Lignocellulosic Biomass for Efficient Hydrolysis and Biofuel Production Industrial \& Engineering Chemical Research 48 (8) 2009: pp. 3713 - 3729.

12. Carvalheiro, F., Duarte, L. C., Gírio, F. M. Hemicellulose Biorefineries: a Review on Biomass Pretreatments Journal of Scientific and Industrial Research 67 2008: pp. 849-864.

13. Obolenskaya, A.V., Elnitskay, Z.P., Leonovich, A.A. Laboratory Manual on Wood and Cellulose Chemistry. Ecologia, Moscow, 1991: pp. 96-99, 161-168.

14. ASTM D638. Standard Test Method for Tensile Properties of Plastics. ASTM International, West Conshohocken, PA, 2007.

15. DIN EN ISO 178: Plastics. Determination of Flexural Properties. European Committee of Standardization, Brussels, EU, 2003.

16. Li, X., Tabil, L.G., Panigrahi, S. Chemical Treatments of Natural Fiber for Use in Natural Fiber-reinforced Composites: a Review Journal of Polymers and the Environment 15 2007: pp. 25-33.

17. Kabir, M. M., Wang, H., Lau, K. T., Cardona, F. Chemical Treatments on Plant-based Natural Fiber Reinforced Polymer Composites: An Overview Composites B 43 2012: pp. 2883-2892.

18. Laka, M., Chernyavskaya, S., Shulga, G., Shapovalov, V., Valenkov, A., Tavroginsakya, M. Use of CelluloseContaining Fillers in Composites with Polypropylene Materials Science (Medžiagotyra) 17 (2) 2011: pp. $151-154$.

19. Shulga, G., Shakels, V., Aniskevicha, O., Zakharova, J., Skudra, S. Interfacial Properties of Polyelectrolyte Complexes Incorporating Kraft Lignin Holzforschung 63 (6) 2009: pp.711-714 